\title{
Transrectal endoscopic ultrasound-guided drainage of pelvic abscess with placement of a fully covered self-expandable metal stent
}

Pelvic abscess developed in an 88-year-old woman (Case 1) following a Hartmann's procedure for a perforated diverticulum and in a 78-year-old woman (Case 2) after diverticulitis ( Fig. 1). Conservative management was unsuccessful in the first patient due to advanced age and in the second patient due to severe co-morbidities.

Both patients underwent transrectal endoscopic ultrasound (EUS)-guided drainage of the pelvic abscess using the same technique, with placement of a transmural fully covered self-expandable metal stent (SEMS) ( Video 1). Briefly, a 19-gauge needle was introduced into the collection using a linear echoendoscope. A 0.035inch wire was then positioned in the cavity and a pre-cut needle-knife was used to create a fistula. A $10 \times 40 \mathrm{~mm}$ fully covered SEMS (WallFlex; Microvasive Endoscopy, Boston Scientific Corp., Natick, Massachusetts, USA) was then placed over the guide wire.

After the procedure, the patients improved substantially and were discharged home after 5 and 6 days, respectively.

In both patients, computed tomography (CT) of the pelvis 2 weeks later showed resolution of the abscess ( Fig. 2 ). The fully covered SEMSs were then removed by rectoscopy a week later.

A follow-up CT 1 month later revealed complete resolution of the abscess in both patients without recurrence ( Fig. 3 ).

Recently, EUS-guided drainage has been proposed as a minimally invasive alternative for the drainage of pelvic abscesses [1-3]. Taking into account the available published data, a drainage catheter and

\section{Video 1}

Transrectal endoscopic ultrasound-guided drainage of pelvic abscess with placement of a fully covered self-expandable metal stent.

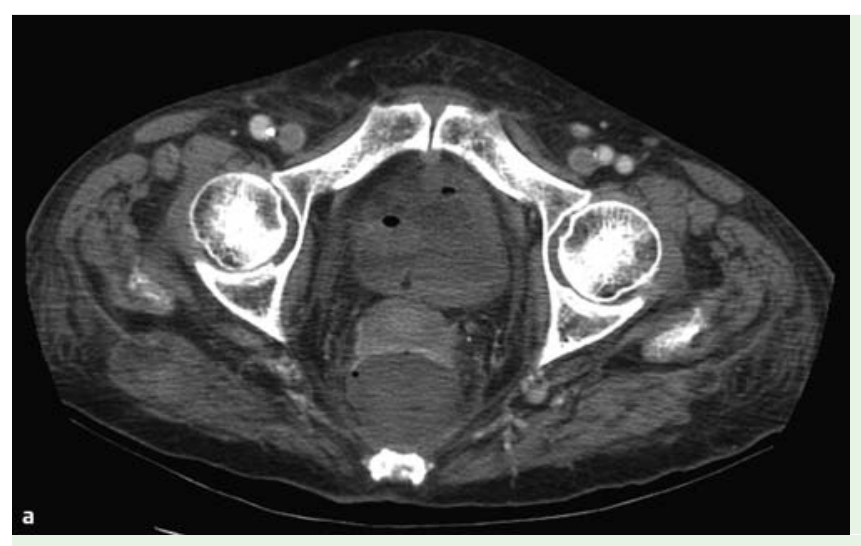

Fig. 1 Computed tomography showing a pelvic abscess. a Case 1. b Case 2.

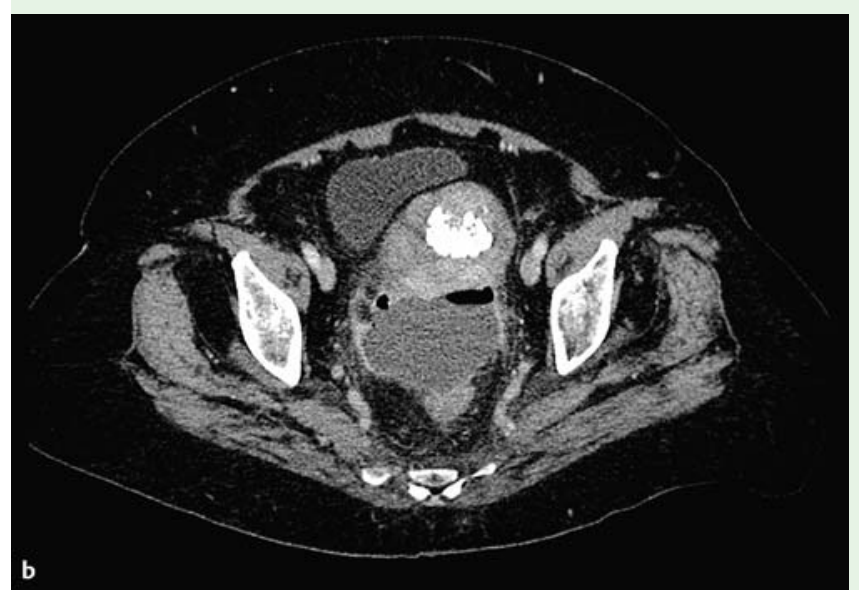

one or two plastic stents for each lesion seem to be the best endoscopic approach [1 -3]. Fully covered SEMSs have also recently been adopted for the drainage of infected pancreatic fluid collections with good results [4].

To the best of our knowledge, these are the first two cases of a fully covered SEMS used for transrectal EUS-guided drainage of pelvic abscesses. We think that the use of these stents can give good results for the drainage of pelvic abscesses.

\section{Endoscopy_UCTN_Code_TTT_1AS_2AZ}

\section{Competing interests: None}

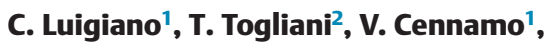
A. Maimone ${ }^{1}$, A. M. Polifemo ${ }^{1}$, S. Pilati ${ }^{2}$, C. Fabbri ${ }^{1}$

${ }^{1}$ Unit of Gastroenterology and Digestive Endoscopy, AUSL Bologna BellariaMaggiore Hospital, Bologna, Italy

2 Unit of Digestive Endoscopy, Carlo Poma Hospital, Mantova, Italy 


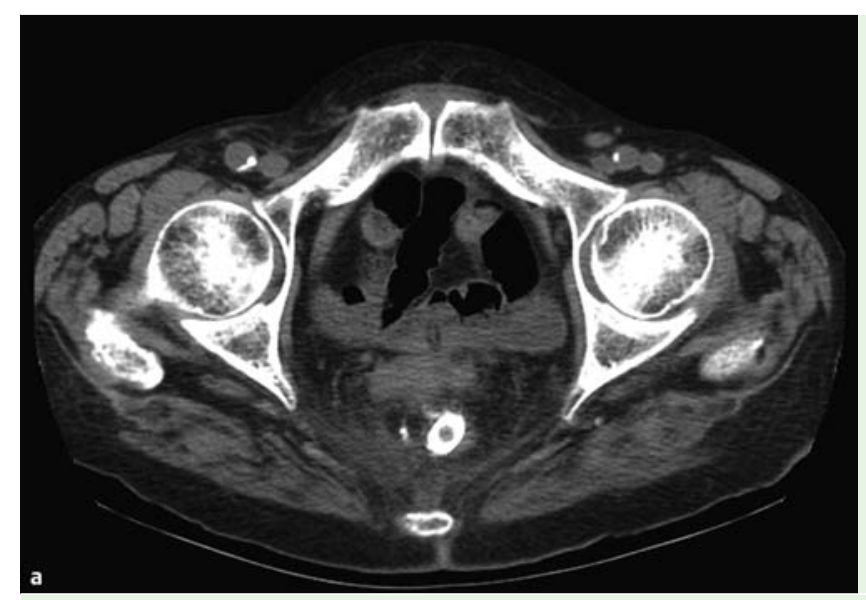

Fig. 2 Computed tomography 2 weeks after drainage, showing resolution of the abscess with transrectal stents visible within the abscess cavity and rectum. a Case 1. b Case 2.
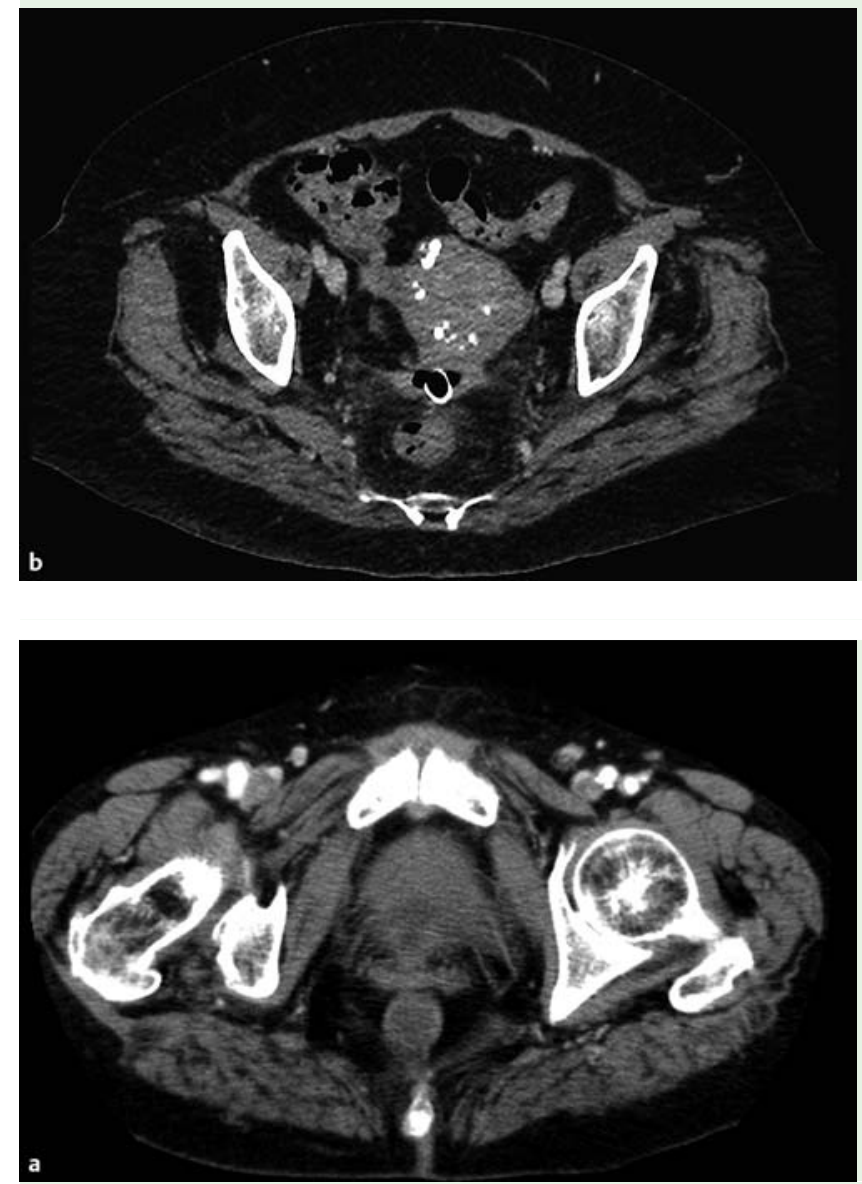

Fig. 3 Computed tomography 1 month after stent removal showing resolution without recurrence of the pelvic abscess. a Case 1. b Case 2.

\section{References}

1 Giovannini M, Bories E, Moutardier $V$ et al. Drainage of deep pelvic abscesses using therapeutic echo endoscopy. Endoscopy 2003; 35: $511-514$

2 Trevino JM, Drelichman ER, Varadarajulu S. Modified technique for EUS-guided drainage of pelvic abscess (with video). Gastrointest Endosc 2008; 68: 1215-1219

3 Varadarajulu S, Drelichman ER. Effectiveness of EUS in drainage of pelvic abscesses in 25 consecutive patients (with video). Gastrointest Endosc 2009; 70: 1121 - 1127

4 Fabbri C, Luigiano C, Cennamo V et al. Endoscopic ultrasound-guided transmural drainage of infected pancreatic fluid collections with placement of covered self-expanding metal stents: a case series. Endoscopy 2012; 44: 429-433

\section{Bibliography}

DOI http://dx.doi.org/

10.1055/s-0032-1326250

Endoscopy 2013; 45: E245-E246

(c) Georg Thieme Verlag KG

Stuttgart · New York

ISSN 0013-726X

\section{Corresponding author}

\section{Fabbri, MD}

Unit of Gastroenterology and Digestive Endoscopy AUSL Bologna

Bellaria Hospital

Via Altura

40139 Bologna

Italy

Fax: +39-051-6225247

carlo.fabbri@ausl.bologna.it

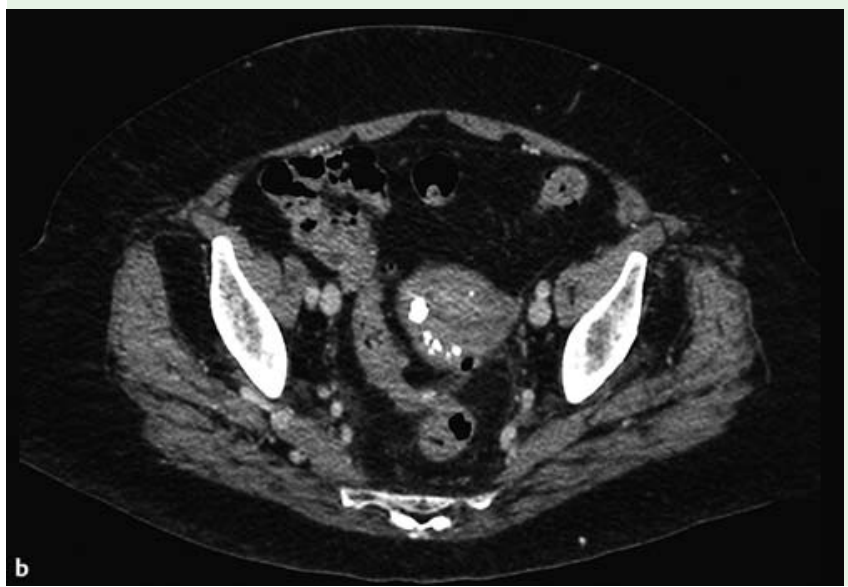

